\title{
FSH-induced ovulation in intact and hypophysectomized mice*
}

\author{
V. Montgomery $\uparrow$, D. Loutradis $\nmid \S$, D. Tulchinsky $\uparrow \uparrow$ and A. Kiessling $\dagger \ddagger$ \\ $\dagger$ Department of Obstetrics, Gynecology, and Reproductive Biology, and the $\ddagger$ Laboratory of Human \\ Reproduction and Reproductive Biology, Harvard Medical School, Brigham \& Women's Hospital, \\ Boston, MA 02115, U.S.A.
}

\begin{abstract}
Summary. A single, ovulatory dose of $25 \mu \mathrm{g}$ of a highly purified preparation of ovine FSH caused ovulation in $89 \%$ of hypophysectomized and $91 \%$ of intact female mice primed $48 \mathrm{~h}$ earlier with PMSG; the number of oocytes recovered $(29.4 \pm 4.7$ and $22 \pm 2 \cdot 7$ /mouse ovulating, respectively) compared favourably with the $20 \cdot 0 \pm 2 \cdot 9$ oocytes per ovulating female recovered from animals that received PMSG $+\mathrm{hCG}$. After oFSH injection, $82 \%$ of oocytes released were fertilized and developed to blastocysts. That the trace contamination $(<0.2 \%)$ of the oFSH with oLH was not responsible for the ovulation was shown by the markedly reduced number of oocytes collected from ovulating females that were injected with equivalent low levels of hCG $(0.001 \mu \mathrm{g})$ or oLH $(1 \mu \mathrm{g})(9 \cdot 0 \pm 3 \cdot 3$ and $8 \cdot 0 \pm 3 \cdot 1$, respectively). These results demonstrate that oFSH is as effective as $\mathrm{LH}$ in inducing ovulation of competent oocytes in the mouse.
\end{abstract}

Keywords: FSH; ovulation; hypophysectomy; mice

\section{Introduction}

The evidence for the role of luteinizing hormone ( $\mathrm{LH}$ ) in triggering ovulation includes the sharp rise in circulating blood concentrations immediately before ovulation (Hoff et al., 1983) and the induction of ovulation by the exogenous administration of human chorionic gonadotrophin (hCG) or LH (Vande Weile et al., 1970). The rising concentrations of LH are thought to initiate a cascade of events that include the resumption of meiosis in the oocyte, luteinization of granulosa cells and synthesis of prostaglandins, all essential for follicle rupture and ovulation (Tsafriri et al., 1972; LeMaire et al., 1975; Fritz \& Speroff, 1982).

The role that follicle-stimulating hormone (FSH) plays in oocyte maturation and ovulation induction is less well understood. FSH is known to rise temporally with $\mathrm{LH}$ immediately before ovulation (McClintock \& Schwartz, 1968; Parkening et al., 1982; Hoff et al., 1983), is more effective than LH in inducing oocyte maturation in cultured follicles (Neal \& Baker, 1975) and has been shown to have a direct role in preovulatory events such as production of plasminogen activator by granulosa cells which then convert the plasminogen to plasmin which weakens the follicle wall (Strickland \& Beer, 1976). Moreover, FSH, but not LH, is known to stimulate cumulus expansion through the synthesis and deposition of an hyaluronic acid matrix, thus allowing the oocytecumulus cell mass to become free floating in the antral fluid before follicle rupture (Eppig, 1979). Studies in rodents suggest that FSH stimulates an increase in cAMP in the follicle, resulting in a delay in meiotic resumption in the cumulus cell-enclosed mouse oocyte (Salustri et al., 1985). This

\footnotetext{
* Reprint requests to A. Kiessling.

§Present address: Hospital Alexandra, University of Athens, Athens, Greece.

ๆPresent address: The Montreal General Hospital, 1650 Cedar, Montreal, Quebec, Canada H3G IA4.
} 
raises the possibility that FSH may be an important mediator in synchronization of oocyte cytoplasmic maturation and germinal vesicle breakdown.

Previous studies in intact and hypophysectomized rodents have suggested that FSH alone may induce ovulation (Lostroh \& Johnson, 1966; Harrington \& Elton, 1969; Stern \& Schuetz, 1970). The experiments used partly purified sheep FSH that contained 1-7\% LH contamination, and did not address the ability of the oocytes to undergo fertilization and cleavage. With the availability of a highly purified sheep FSH preparation $(0 \cdot 2 \%$ LH contamination), we have undertaken this study to determine the effect of a single high dose of FSH on oocyte maturation and ovulation induction in intact and hypophysectomized mice primed with PMSG. In addition, we studied the ability of the sheep FSH preparation to induce maturation of oocytes capable of undergoing fertilization and subsequent development to the blastocyst stage.

\section{Materials and Methods}

Gonadotrophins. PMSG and hCG were obtained from Sigma Chemical Company (St Louis, MO). FSH from pig pituitaries (FSH-P) was obtained from Burns-Biotec Laboratories (Omaha, NE) and is the same FSH preparation previously used in large animal studies (Kiessling et al., 1986). Sheep FSH (oFSH) and sheep LH (oLH) were obtained from the National Institutes of Health Hormone and Pituitary Program (Bethesda, MD). The dose of $25 \mu \mathrm{g}$ oFSH (20 i.u. $/ \mathrm{mg}$ ) used in the studies reported here was considered to contain $<0.2 \%$ oLH (Lostroh \& Johnson, 1966; Technical Report No. 156) by an ovarian ascorbic acid depletion bioassay. The dose of $\mathrm{oLH}(1 \mu \mathrm{g})$ was equivalent to the LH contamination of $25 \mu \mathrm{g}$ oFSH by weight, and was considered to be $99 \%$ free of oFSH by radioimmunoassay (Technical Report No. 156 of the Pituitary Hormones and Antisera Center, NIADDK, Bethesda, MD).

Animals. Sexually mature female mice of the CD-1 strain, 42-52 days of age, and mature CD-1 males were obtained from Charles River Breeding Laboratories, Wilmington, MA; B602F-1 males were from Jackson Laboratories, Bar Harbor, ME. Animals were housed 6-12 to a cage for at least 5 days after arrival, in a daily light:dark cycle of $12 \mathrm{~h}$ each (lights on 06:00 h). Hypophysectomized CD-1 females, 42-52 days of age, were also obtained from the Charles River Breeding Laboratories about $72 \mathrm{~h}$ after the surgery. These animals were housed 6 to a cage in well-insulated cages with a filter-top cover. All animals were fed pelleted food ad libitum; the intact animals drank routine animal facility water, and hypophysectomized animals were offered $5 \%$ dextrose in water. Hypophysectomized animals were injected with the hormones described at least $96 \mathrm{~h}$ after surgery.

Ovulation induction. Females were selected at random stages of the oestrous cycle and injected i.p. with 5 i.u. PMSG in 0.1 ml 0.154 M- NaCl between 16:00 and 16:30 h. After $48 \mathrm{~h}$, intact animals were divided into the following ovulation induction groups, 5 i.u. hCG $(\mathrm{N}=12), 25 \mu \mathrm{g} \mathrm{FSH-P}(\mathrm{N}=7), 25 \mu \mathrm{g}$ FSH $(\mathrm{N}=22), 0 \cdot 1 \mathrm{ml} 0.154 \mathrm{M}-\mathrm{NaCl}$ $(\mathrm{N}=10)$, no handling $(\mathrm{N}=10), 0.001$ i.u. hCG $(\mathrm{N}=10), 0.01$ i.u. hCG $(\mathrm{N}=10), 1 \mu \mathrm{g} \mathrm{LH}(\mathrm{N}=12)$, and injected as described above. Hypophysectomized animals $(N=9)$ were also given an injection of $25 \mu \mathrm{g}$ oFSH $48 \mathrm{~h}$ later. About $17-20 \mathrm{~h}$ after the second injection, the animals were killed by cervical dislocation, and oviducts and associated ovaries were removed and placed in a solution of Dulbecco's phosphate-buffered saline containing $4 \mathrm{mg}$ bovine serum albumin $/ \mathrm{ml}$. Oviducts and ovaries were trimmed with the aid of a dissecting microscope, and the ovarian bursae were examined for the presence of oocytes. As necessary, the oviducts were punctured or flushed to ensure recovery of all oocytes released. After recovery of the oocytes, hyaluronidase $(265 \mathrm{i} . \mathrm{u} . / \mathrm{ml})$ was added to remove the cumulus cells, allowing individual oocytes to be counted. All oocytes released or flushed from the oviducts were counted and the presence of a polar body was noted.

Fertilization and embryo culture. The breeding experiments were accomplished by caging the CD-1 females individually with males of the BDF-1 or CD-1 strain immediately after the second injection of gonadotrophin. The females were examined the following morning for the presence of a copulation plug which was taken as an indication of mating. Approximately $24 \mathrm{~h}$ later, the females were killed and each oviduct was removed and flushed as previously described (Kiessling \& Weitlauf, 1979) to recover 2-cell embryos. Embryos were cultured in groups of 20 in modified Kreb's-Ringer bicarbonate (Biggers et al., 1968; Loutradis et al., 1987) under an atmosphere of $5 \% \mathrm{CO}_{2}$ in air for $64 \mathrm{~h}$ before examination to determine development to blastocysts.

Statistics. Comparisons of oocytes collected from each treatment group were by unpaired Student's $t$ tests.

\section{Results}

\section{Ovulatory response of PMSG-primed animals}

Of the animals receiving the FSH preparation, 91-100\% ovulated a mean of $24 \cdot 1 \pm 3.5$ (s.e. of the mean) and $22.0 \pm 2.7$ oocytes for the oFSH and FSH-P, respectively; $67 \%$ of the animals 
receiving the hCG ovulated a mean of $20 \cdot 0 \pm 2.9$ oocytes (Fig. 1). Although the oocyte recovery per animal that ovulated was approximately the same for all 3 groups, the oocyte recovery per animal injected was actually greater for the FSH groups than for the hCG groups $(P \leqslant 0.15$ for oFSH and $\leq 0.05$ for FSH-P). Of the animals receiving the normal saline injection, $90 \%$ ovulated a mean of $4 \cdot 1 \pm 1 \cdot 3$ oocytes, significantly fewer than the animals receiving gonadotrophins $(P \leq 0.001)$. In contrast, only $40 \%$ of the animals receiving no second injection ovulated a mean of $2 \cdot 3 \pm 0.8$ oocytes per animal, significantly fewer than the group receiving the normal saline $(P \leq 0 \cdot 02)$ (Fig. 1).
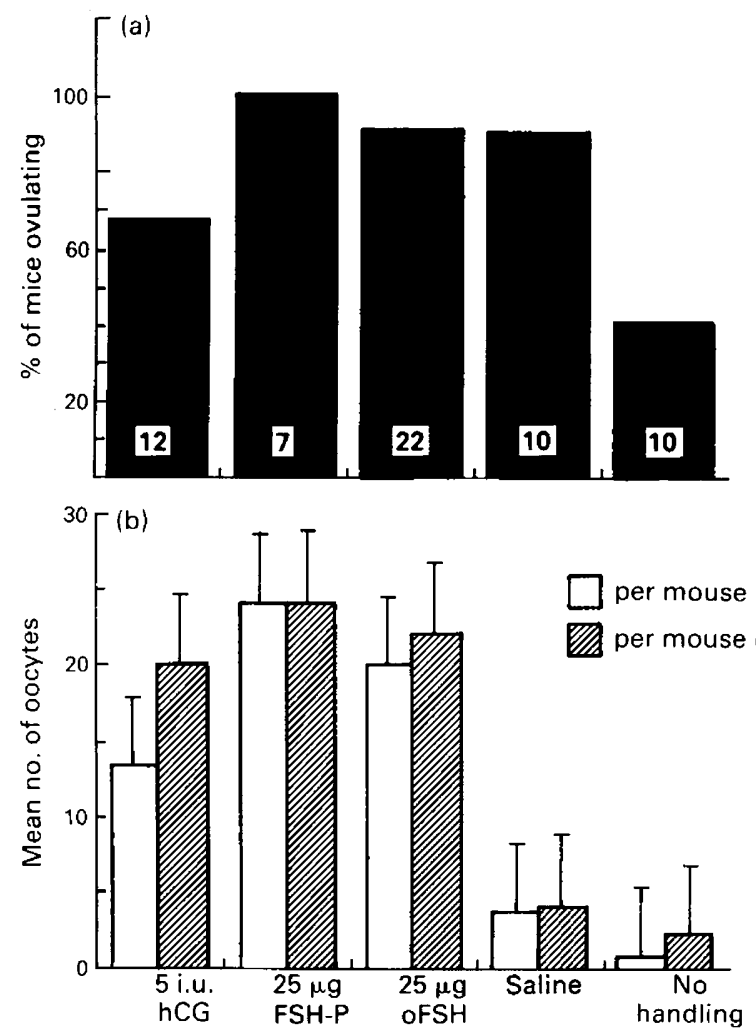

Fig. 1. Responses of mice to ovulation induction regimens. Gonadotrophin treatments were as described in 'Materials and Methods'. Values are mean \pm s.e. for the no. of animals indicated in (a).

When PMSG-primed animals were injected with low doses of hCG or oLH (Fig. 2), 50\% of the animals that received 0.001 i.u. hCG (equivalent to the $0.2 \%$ contamination in the oFSH preparation) ovulated a mean of $9 \cdot 0 \pm 3 \cdot 3$ oocytes per animal, a result similar to the group that received 0.01 i.u. hCG (equivalent to 10 times the estimated LH contamination in the oFSH preparation) of which $50 \%$ of the animals ovulated $8.8 \pm 3.6$ oocytes. In the animals that received $1 \mu \mathrm{g}$ oLH (equivalent to $0 \cdot 2 \%$ of the oFSH by weight), $42 \%$ ovulated a mean of $8 \cdot 0 \pm 3 \cdot 1$ oocytes. These results were significantly different $(P \leq 0.002)$ from those obtained with oFSH-injected animals, and in the range of the results obtained with the normal saline-injected animals $(P \leq 0 \cdot 75)$. 

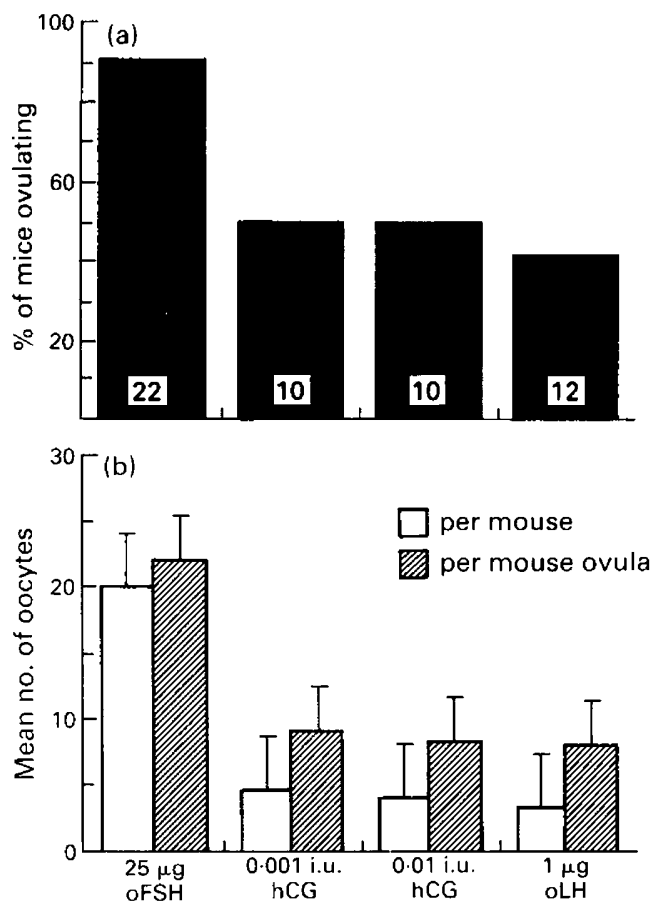

Fig. 2. Comparison of ovulation rates using doses of $\mathrm{LH} \geq$ the low level of contamination found in oFSH. Gonadotrophin treatments were as described in 'Materials and Methods'. Values are mean \pm s.e. for the no. of mice indicated in (a).

\section{Ovulatory response of $P M S G$-primed hypophysectomized animals}

When 7 hypophysectomized females were primed with PMSG (5 i.u.) and injected with oFSH, $89 \%$ of the animals ovulated a mean of $29 \cdot 4 \pm 4 \cdot 7$ oocytes, similar to the response of intact animals $(P \geq 0 \cdot 29)$.

\section{Developmental ability of oFSH-induced oocytes}

When 7 females primed with 5 i.u. PMSG and injected with an ovulatory dose of $25 \mu \mathrm{g}$ oFSH were mated with fertile males to determine the developmental potential of the oocytes released, $17 \cdot 0 \pm 1 \cdot 0$ two-celled embryos per female were recovered, $70 \%( \pm 10)$ of which developed into blastocysts after $64 \mathrm{~h}$ in vitro. These results were not statistically significantly different from the results obtained for 8 females injected with 5 i.u. hCG ( $16 \pm 2$ embryos/female, $83 \pm 3 \%$ blastocysts).

\section{Discussion}

These results show that a single, ovulatory dose of FSH is as effective as hCG in inducing ovulation of mouse oocytes capable of apparently normal fertilization and cleavage. Although many animals in the control treatment groups ovulated a small number of oocytes, neither the LH contamination of the FSH (reported to be $0 \cdot 2 \%$, i.e. equivalent to 0.001 i.u. hCG) nor the residual LH activity from the PMSG-priming injection accounted for the $\geq 20$ oocytes per female collected after the FSH injections. The collection of 29 oocytes per ovulating, hypophysectomized female rules out the possibility that an endogenous release of $\mathbf{L H}$ by the pituitary was responsible for ovulation as suggested by Christensen \& Eleftheriou (1972). 
The ovulatory dose of $25 \mu \mathrm{g} \mathrm{FSH}$ would achieve maximal blood concentrations of $1-2 \mu \mathrm{g} / \mathrm{ml}$, probably within the physiological range since the preovulatory rise of FSH in mice has been reported to reach $\sim 0.6 \mu \mathrm{g} / \mathrm{ml}$ (Parkening et al., 1982). Previous studies by other investigators have also documented ovulation in rats after FSH injections, although fewer oocytes were recovered per animal and less pure preparations of FSH were used (Lostroh \& Johnson; 1966; Harrington \& Elton, 1969; Stern \& Schuetz, 1970).

That FSH alone induces maturation and ovulation of oocytes competent to undergo fertilization and cleavage raises the possibility that FSH may be more important than LH in this process. Salustri et al. (1985) have shown that oFSH induces an increase in cAMP in cumulus cell-enclosed mouse oocytes. This increase in cAMP was shown to correlate with a delay in the resumption of meiosis following an injection of FSH in the cumulus cell mass in vitro; as levels of cAMP decrease, meiosis resumes, with germinal vesicle breakdown (Salustri et al., 1985). The rise in cAMP is not seen in denuded oocytes, suggesting that the cAMP is supplied by the cumulus cell and possibly transferred to the oocyte via gap junctions (Salustri et al., 1985). Such an FSH-induced delay of meiosis could play a critically important role in maintaining the germinal vesicle throughout the stage of cytoplasmic maturation of the oocyte, thus allowing for synchronization of oocyte maturation and the resumption of meiosis. Our experimental results support the evidence that oFSH induces oocyte maturation but the mechanism of follicle rupture by oFSH remains unclear.

However, Tsfariri et al. (1972) have demonstrated that an increase in cAMP by LH causes immediate resumption of meiosis with completion of the first meiotic division in rats. This apparent contradiction in the role of gonadotrophin-induced changes in CAMP in oocyte maturation and ovulation requires further investigation.

It is possible that, if $\mathrm{LH}$ is allowed to act in the absence of $\mathrm{FSH}$, meiosis may resume prematurely, resulting in germinal vesicle breakdown and oocytes not fully competent to undergo fertilization and cleavage. This hypothesis is supported by several observations. Administration of hCG to goats primed with PMSG results in decreased rates of ovulation and fertilization (Burry et al., 1986). Superovulation is best achieved with FSH preparations that do not have LH activity with a long half-life (Kiessling et al., 1986).

An ovulatory dose of hCG administered to hMP- or clomiphene citrate-primed women undergoing ovulation induction may cause asynchrony between oocyte maturation and cumulus cell expansion, possibly resulting in oocytes that may resume meiosis before completion of cytoplasmic maturation (Laufer et al., 1984). The administration of hCG in these patients is not accompanied by a peak in FSH. In addition, lower rates of fertilization are observed in patients with serum $\mathrm{LH}$ concentrations greater than one standard deviation above the mean follicular-phase serum LH value of $13.9 \mathrm{i} . \mathrm{u} . / \mathrm{l}$ (Laufer et al., 1984). These authors proposed that the reduced fertilization could be a reflection of premature oocyte maturation or ageing secondary to an increase in the basal concentration of LH (Stranger \& Yovich; 1985). In summary, the FSH peak that accompanies the mid-cycle LH peak may transiently prolong the resumption of meiosis and thus balance oocyte cytoplasmic maturation with the LH-induced effects on the follicle.

We thank D. John, K. Jackson and R. Crowell for technical support.

Supported in part by the Commonwealth Fund Medical Fellowship Program of the National Medical Fellowships, Inc., New York, NY, and grant HP-21890 from the National Institutes of Child Health and Human Development.

\section{References}

Biggers, J.D., Whitten, W.K. \& Whittingham, D.G. (1968)

The culture of mouse embryos in vitro. In Methods of Mammalian Embryology, pp. 86-116. Ed. J. C. Daniel

Jr. Freeman and Company, San Francisco.
Burry, K.A., Kiessling, A.A. \& Blankevoot, M. (1986) Superovulation of large breed goats estrus-regulated with progesterone or prostaglandin $\mathrm{F}_{2} \alpha . J$. In Vitro Fert. \& Embryo Transfer 3, 163-164. 
Christenson, C.M. \& Eleftheriou, B.E. (1972) Dose dependence of superovulation response in mice to two injections of PMSG. J. Reprod. Fert. 19, 287-291.

Eppig, J.J. (1979) Gonadotrophin stimulation of the expansion of cumulus oophori isolated from mice: general conditions of expansion in vitro. J. exp. Zool. 208, $111-120$.

Fritz, M.A. \& Speroff, L. (1982) The endocrinology of the menstrual cycle: the interaction of folliculogenesis and neuroendocrine mechanisms. Fert. Steril. 38, 509-531.

Harrington, F.E. \& Elton, R.L. (1969) Induction of ovulation in adult rats with follicle stimulating hormone. Proc. Soc. exp. Biol. Med. 132, 841-844.

Hoff, J.D., Quigley, M.E. \& Yen, S.S.C. (1983) Hormonal dynamics at midcycle: a reevaluation. J. clin. Endocr. Metab. 57, 792-796.

Kiessling, A.A. \& Weitlauf, H.M. (1979) DNA polymerase activity in preimplantation mouse embryos. $J$. exp. Zool. 208, 347-354.

Kiessling, A.A., Hughes, W.H. \& Blankevoort, M.R. (1986) Superovulation and embryo transfer in the dairy goat. J. Am. vet. med. Assoc. 188, 829-832.

Laufer, N., Tarlatzis, B., Decherney, A., Masters, J.T., Haseltine, F.P., Maclusky, N. \& Naftolin, F. (1984) Asynchrony between human cumulus corona cell complex and oocyte maturation after human menopausal gonadotrophin treatment for in vitro fertilization. Fert. Steril. 42, 366-371.

LeMaire, W.J., Leidner, R. \& Marsh, J.M. (1975) Pre and post ovulatory changes in the concentration of prostaglandins in rat graffian follicles. Prostaglandins 9, 221-225.

Lostroh, A.J. \& Johnson, R.E. (1966) Amounts of interstitial cell-stimulating hormone and follicle stimulating hormone required for follicular development, uterine growth and ovulation in the hypophysectomized rat. Endocrinology 79, 991-996.

Loutradis, D., John, D. \& Kiessling, A.A. (1987) Hypoxanthine causes a two-cell block in randombred mouse embryos. Biol. Reprod. 37, 311-316.
McClintock, J.A. \& Schwartz, N.B. (1968) Changes in pituitary and plasma follicle stimulating hormone concentrations during the rat estrous cycle. Endocrinology 83, 433-441.

Neal, P. \& Baker, T.T. (1975) Response of mouse Graafian follicles in organ culture to varying doses of follicle-stimulating hormone and luteinizing hormone. J. Endocr. 65, 27-32.

Parkening, T.A., Collins, T.J. \& Smith, E.R. (1982) Plasma and pituitary concentrations of LH, FSH, and prolactin in aging $\mathrm{C} 57 \mathrm{BL} / 6$ mice at various times of the estrous cycle. Neurobiol. Aging 3, 31-35.

Salustri, A., Petrungaro, S., DeFelici, M., Conti, M. \& Siracusa, G. (1985) Effect of follicle-stimulating hormone on cyclic adenosine monophosphate level and on meiotic maturation in mouse cumulus cellenclosed oocytes cultured in vivo. Biol. Reprod. 33, $797-802$.

Stern, S. \& Schuetz, A.W. (1970) Asynchrony of ovulation and mating in mice treated with gonadotrophins. J. Reprod. Fert. 23, 257-261.

Stranger, J.D. \& Yovich, J.L. (1985) Reduced in-vitro fertilization of human oocytes from patients with raised basal luteinizing hormone levels during the follicular phase. Br. J. Obstet. Gynaec. 92, 385-393.

Strickland, S. \& Beer, N.H. (1976) Studies on the role of plasminogen activation in ovulation. J. biol. Chem. 251, $5694-5702$.

Tsafriri, A., Lindner, H.R., Zor, U. \& Lamprecht, S.A. (1972) In-vitro induction of meiotic division in follicle-enclosed rat oocytes by LH, cyclic AMP and prostaglandin $\mathrm{E}_{2}$. J. Reprod. Fert. 31, 39-50.

Vande Weile, R.J., Bofumil, J., Dyrenfurth, I., Ferin, M., Jewelewicz, R., Warren, M., Rizkallah, T. \& Mikhail, G. (1970) Mechanisms regulating the menstrual cycle in women. Recent Progr. Horm. Res. 26, 63-103. 